\title{
NGHIÊN CỬU LỰA CHỌN MẠNG LƯỚI TRẠM KHÍ HẬU THAM CHIẾU PHỤC VỤ GIÁM SÁT TÁC ĐộNG BĐKH CHO KHU VỬC NAM BỘ
}

\author{
Đặng Thanh Mai ${ }^{1}$
}

Tóm tắt: Mạng khi hậu tham chiếu là mạng bao gồm các trạm khi tương với mục tiêu giám sát biến đổi khi hậu (BĐKH) và tác động của BĐKH. Mục tiêu của mạng luới này là cung cấp các quan trắc đồng nhất về nhiệt độ và luợng mưa tù các trạm chuẩn, kết hợp với các quan trắc trong quá khư để phát hiện và ghi nhận sụ thay đổi khí hậu. Nghiên cứu này đề xuất phuoong pháp và quy trình uoóc tính số lương và lựa chọn các trạm khí tượng cho mạng khí hậu tham chiếu, úng dụng cho vùng khi hậu Nam bộ. Nghiên cứ được thục hiện bằng cách hình thành các mạng giả thuyết tù các trạm trong mạng trạm co bản hiện có. Kỹ thuật lấy mẫu lại Monte Carlo được áp dụng cho các trạm trong khu vưc để giảm số trạm liên tiếp so với mạng cơ sở. Số lượng trạm tham chiếu thích hợp được xác định là số lượng trạm cần thiết để tạo lại, trong giới hạn sai số được xác định trước, xu hướng nhiệt độ và mua hàng năm đã quan trắc được trên lãnh thổ. Việc lựa chọn tổ hợp các trạm dựa trên việc phân tích đánh giá các tiêu chi về sai số giá trị trung bình, sai số xu thế biến đổi, hệ số tuoong quan của yếu tố đánh giá và phân bố theo không gian các trạm. Số luợng và tổ hợp các trạm được xác định riêng cho giám sát các yếu tố nhiệt độ trung bình năm, nhiệt độ cao nhất năm, nhiệt độ thấp nhất năm và tổng lương mưa. Mạng khi hậu tham chiếu cho khu vưc Nam Bộ gồm 11 trạm khí tuợng được lự chọn thỏa mãn muc tiêu xu thế biến đổi nhiệt độ là $0.05^{\circ} \mathrm{C} /$ thập kỷ và muc tiêu xu thế biến đổi của tổng lượng mưa là 1,0\%/thạp kỷ.

Từ khóa: Mạng khí hậu tham chiếu, giám sát BĐKH, vùng khỉ hậu Nam Bộ.

Ban Biên tập nhận bài: 15/03/2019 Ngày phản biện xong: 08/05/2019 Ngày đăng bài: 25/05/2019

\section{Mở đầu}

Hầu hết các trạm khí tượng trong mạng lưới trạm KTTV cơ bản tại Việt Nam được thiết lập với mục tiêu quan trắc sự thay đổi điều kiện khí tượng và dự báo thời tiết. Dữ liệu từ các trạm này cũng được sử dụng rộng rãi trong việc phát hiện sự thay đổi khí hậu và đánh giá tác động của biến đổi khí hậu đặc biệt là đánh giá sự biến đổi theo thời gian so với trung bình của thông số khí hậu trên một khu vực cụ thể. Mạng lưới các trạm khí tượng tham chiếu được xây dựng trên nền mạng lưới trạm khí tượng cơ sở bao gồm các trạm có chất lượng cao và có tính đại diện theo không gian được lựa chọn từ mạng lưới các trạm cơ bản. Mục tiêu của nghiên cứu này là xây dựng ${ }^{1}$ Tổng cục Khí tương Thủy văn Email: thanhmaidang1973@gmail.com một phương pháp xác định mạng trạm khí tượng tham chiếu tối ưu sử dụng trong giám sát sự biến đổi các yếu tố khí hậu và tác động $B Đ K H$ đến cực trị các yếu tố khí tượng và các hiện tượng khí tượng nguy hiểm ở Việt Nam. Việc xác định mạng trạm tham chiếu tối ưu cần giải quyết 2 vấn đề chính là xác định được số lượng trạm tối ưu cho giám sát đảm bảo yêu cầu và lựa chọn tổ hợp các trạm phù hợp đưa vào mạng lưới trạm. Giả sử rằng mạng trạm cơ bản hiện tại đủ dày để có thể xác định được các đặc trưng thực của khí hậu khu vực bằng cách tính trung bình theo không gian. Quá trình giảm độ phân giải mạng một cách có hệ thống từ mạng cơ sở cho phép định lượng quan hệ giữa mật độ trạm và hiệu suất mạng lưới trạm.

Cách tiếp cận trong tối ưu hóa mạng lưới trạm 
giám sát là giảm độ phân giải mạng một cách có hệ thống từ mạng trạm cơ bản. Điều này được thực hiện bằng cách loại bỏ có chọn lọc một số trạm khỏi cấu hình mạng. Mỗi lần như vậy sẽ tạo các mạng có độ phân giải không gian thấp hơn. Mật độ trạm lý tưởng dùng trong giám sát $\mathrm{BĐKH}$ và tác động $\mathrm{BĐKH}$ là số lượng trạm có thể dùng để mô phỏng lại sát nhất các xu thế biến đổi của các cực trị các yếu tố khí tượng và hiện tượng khi tượng nguy hiểm so với sử dụng mạng cơ bản với các mục tiêu giám sát được xác định trước, ví dụ như xu thế thay đổi nhiệt độ của một khu vực có sai số tuyệt đối trung bình dưới $0,1^{\circ} \mathrm{C}$ mỗi thập kỷ.

Phương pháp phân tích suy thoái mạng được sử dụng để đánh giá các mạng trạm quan trắc khí tượng hoặc thủy văn hiện có và để xác định mật độ mạng cần thiết để đáp ứng mục tiêu giám sát cụ thể. Phương pháp này mô phỏng sự giảm cấp có hệ thống của mật độ mạng trạm và xác định mức độ hiệu quả của từng mạng giảm cấp so với mạng đầy đủ. Phương pháp lấy mẫu Monte Carlo, lựa chọn ngẫu nhiên các trạm từ toàn bộ mạng của các trạm hiện có, được sử dụng để tạo các mạng giảm cấp. Các mạng giảm cấp được tạo là các tập hợp con của mạng đầy đủ, với mật độ dữ liệu không gian ít hơn so với mạng đầy đủ. Phương pháp này đã được nghiên cứu, sử dụng trong thiết lập mạng tham chiếu giám sát BĐKH của Mỹ. Đối với mạng tham chiếu khí hậu Mỹ (CRN), cơ quan Khí quyển và Đại dương Quốc gia (NOAA) đã sử dụng phương pháp này để xác định mật độ không gian và tổng số trạm quan trắc cần thiết để cải thiện khả năng quan sát biến đổi khí hậu theo thời gian trên toàn lãnh thổ Mỹ. Nghiên cứu [7] được thực hiện cho mạng tham chiếu đã chia 48 bang thành 115 ô lưới và trong mỗi ô lưới tạo ra các mạng giả thuyết từ các mẫu con đại diện của các trạm từ mạng cơ sở mật độ cao hơn hiện có. Cách tiếp cận lấy mẫu tương tự đã được sử dụng để kiểm tra ảnh hưởng của cỡ mẫu đến phép nội suy không gian của tổng lượng mưa hàng năm [1] và nhiệt độ trung bình hàng tháng [4].

Mặc dù phương pháp phân tích suy thoái mạng có thể được sử dụng để xác định số lượng trạm và đánh giá mức độ đầy đủ của mật độ trạm hiện tại ở các khu vực, tuy nhiên phương pháp này không trực tiếp xác định được các vị trí các trạm tối ưu để loại bỏ hoặc thêm vào mạng. Nghiên cứu này đề xuất phương pháp lựa chọn tổ hợp các trạm tối ưu trong mạng lưới dựa trên việc đánh giá các tiêu chí về sai số xu thế biến đổi của yếu tố, sai số trung bình yếu tố theo thời gian và hệ số tương quan giữa hai chuỗi yếu tố được xác định từ mạng tối ưu và mạng cơ bản.

Cách tiếp cận bằng phương pháp phân tích suy thoái mạng được minh chứng bằng cách sử dụng dữ liệu nhiệt độ và lượng mưa từ mạng lưới trạm cơ bản của vùng khí hậu Nam bộ để ước tính số lượng trạm cần thiết của mạng trạm khí tượng tham chiếu cho vùng khí hậu Nam Bộ nhằm đáp ứng các mục tiêu giám sát biến đổi khí hậu và tác động của biến đổi khí hậu trong tương lai.

\section{Phương pháp nghiên cứu và thu thập số liệu}

\subsection{Giới thiệu khu vục nghiên cứu}

Theo các nghiên cứu phân vùng khí hậu [6], vùng khí hậu Nam Bộ trải rộng từ chân các cao nguyên Nam Trung Bộ tới mũi Cà Mau. Đặc điểm chung của vùng khí hậu Nam Bộ là nắng nhiều, nhiệt độ quanh năm cao, không có sự phân mùa trong chế độ nhiệt, nhưng phân mùa rất rõ rệt trong chế độ mưa ẩm, mùa mưa về cơ bản trùng với mùa gió mùa mùa hè. Nhiệt độ không khí trung bình năm khoảng $26,5-27,5^{\circ} \mathrm{C}$, biên độ nhiệt năm $3-4^{\circ} \mathrm{C}$; tổng lượng mưa trung bình năm khoảng từ $1600 \mathrm{~mm}$ đến $2500 \mathrm{~mm}$. Hiện nay, mạng trạm cơ bản đo đạc khí tượng trên khu vực có 24 trạm, phần lớn bắt đầu hoạt động sau năm 1979. Mạng lưới trạm khí tượng cơ bản của vùng khí hậu Nam bộ được chọn bao gồm 16 trạm khí tượng đo nhiệt độ, lượng mưa và các yếu tố khí hậu khác trong 39 năm qua (Hình 1). Các trạm này đều có thời gian quan trắc liên tục dài và đang tiếp tục hoạt động; chuỗi số liệu được đánh giá là đồng nhất và có chất lượng cao, nằm ở xa khu vực trung tâm đô thị lớn, không hoặc ít chịu tác động trực tiếp từ các 
hoạt động kinh tế, xã hội mang tính địa phương và có điều kiện hoạt động với hành lang kĩ thuật tiêu chuẩn ổn định lâu dài trong tương lai. Trong suốt thời gian hoạt động, sử dụng các chủng loại máy và thiết bị đo các yếu tố khí tượng cơ bản có cùng tiêu chuẩn về độ chính xác.

\subsection{Thu thập, xử lý dũ liệu}

Dữ liệu cho nghiên cứu là chuỗi số liệu nhiệt độ trung bình năm, cao nhất trung bình năm, nhiệt độ thấp nhất trung bình năm và tổng lượng mưa năm được thu thập từ 16 trạm khí tượng từ 1979 đến nay. Các trạm được lựa chọn là các trạm có chuỗi số liệu tương đối đồng nhất và đủ dài (39 năm số liệu). Nói chung, mạng lưới trạm khí tượng cơ bản được lựa chọn phân bố tương đối đều trên vùng khí hậu Nam Bộ.

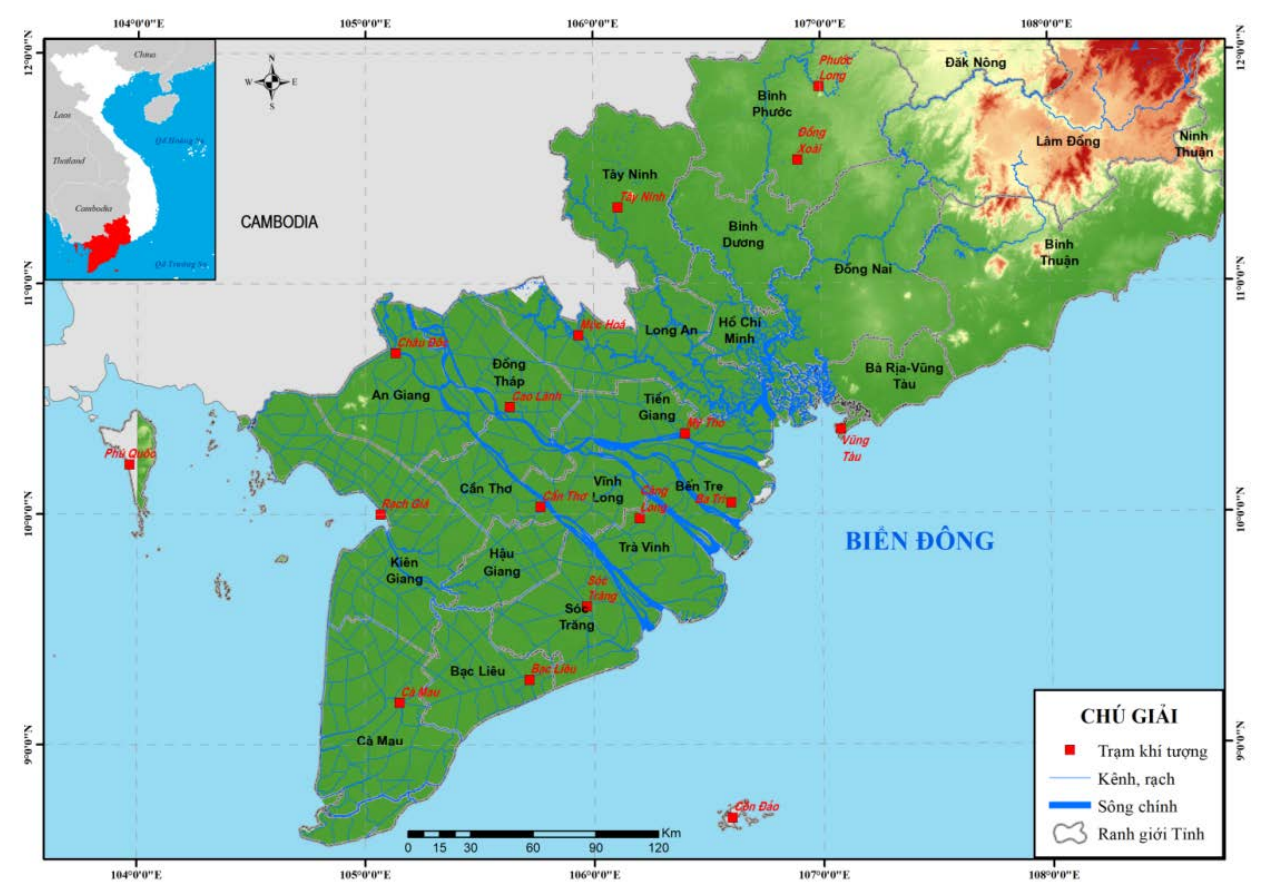

Hình 1. Bản đồ mạng luới trạm khí tượng co bản thuộc vùng khí hậu Nam Bộ

Để loại trừ sự biến đổi theo vĩ độ và địa hình, mỗi giá trị yếu tố hàng năm tại mỗi trạm được biểu thị bằng độ lệch so với giá trị trung bình hàng năm dài hạn của trạm đó. Đối với nhiệt độ, việc chuẩn hóa sẽ thực hiện bằng cách lấy nhiệt độ thực tế của trạm trong năm đó trừ đi nhiệt độ trung bình nhiều năm của trạm: $\mathrm{T}_{\mathrm{Ai}}=\mathrm{T}_{\mathrm{i}}-\mathrm{T}$, Trong đó TAi là sự bất thường của trạm (tính theo ${ }^{\circ} \mathrm{C}$ ) cho năm i, Ti là nhiệt độ thực tế của trạm trong năm $\mathrm{i}, \mathrm{T}$ là nhiệt độ trung bình năm trong giai đoạn cơ sở (1980-2010) của trạm. Sự bất thường về lượng mưa của một trạm được tính bằng cách chia tổng lượng mưa thực tế trong năm đó cho giá trị trung bình trong giai đoạn cơ sở (1980-2010): $\mathrm{P}_{\mathrm{Ai}}=\mathrm{P}_{\mathrm{i}} / \mathrm{P}$. Trong đó $\mathrm{P}_{\mathrm{Ai}}$ là sự chuẩn hóa của trạm (tính bằng phần trăm) cho năm $\mathrm{i}, \mathrm{P}_{\mathrm{i}}$ là tổng lượng mưa của trạm trong năm i và $\mathrm{P}$ là lượng mưa trung bình trong giai đoạn cơ sở (1980-2010) của trạm.

\subsection{Phuơng pháp nghiên cứu}

Nghiên cứu này sử dụng phương pháp phân tích suy thoái mạng Monte Carlo để xác định mật độ trạm tối ưu cho mạng lưới trạm khí tượng giám sát $\mathrm{BĐKH}$ và tác động $\mathrm{BĐKH}$ đối với yếu tố, hiện tượng khí tượng cực đoan trong một khu vực. Phương pháp này thực hiện giảm độ phân giải mạng một cách có hệ thống bằng cách loại bỏ có chọn lọc các trạm khỏi mạng mật độ đầy đủ ban đầu. Mật độ lý tưởng cho mạng trạm khí tượng tham chiếu giám sát BĐKH khí hậu sẽ là mật độ của các trạm mà dữ liệu khi được phân tích sẽ tái tạo được các xu hướng của các yếu tố được xác định từ dữ liệu từ mạng mật độ đầy đủ trong một phạm vi sai số nhất định.

Trong khu vực nghiên cứu, các mạng trạm giảm cấp có độ phân giải không gian thấp hơn 
được xác định bằng cách chọn ngẫu nhiên các tập hợp con của từ mạng trạm cơ sở có mật độ cao hơn. Số lượng trạm trong mỗi tập hợp con được tăng thêm một (1) để tất cả các kích thước tập hợp con từ một đến $\mathrm{N}-1$ được kiểm tra ( $\mathrm{N}$ là tổng số trạm trong một khu vực). Chuỗi thời gian trung bình của các yếu tố giám sát (ví dụ nhiệt độ trung bình hàng năm, các cực trị nhiệt độ, tổng lượng mưa hàng năm, lượng mưa 1 ngày lớn nhất...) tổ hợp từ chuỗi số liệu chuỗi thời gian của từng trạm được tạo cho mỗi mạng trạm hạ cấp.

Quy trình lấy mẫu lại Monte Carlo được áp dụng để tạo ra 10.000 kịch bản khác nhau cho mỗi kích thước mạng trạm hạ cấp. Quy trình này giải quyết ảnh hưởng của nhiều cấu hình mạng, làm giảm hiệu ứng của các mạng trạm hạ cấp phân bố không đều. Xu thế tổ hợp của yếu tố giám sát được xác định từ đó tính toán được sai số xu thế của yếu tố giám sát cho mỗi mạng giảm cấp. Khi các mục tiêu giám sát hay ngưỡng giám sát mong muốn được xác định sẽ xác định được mật độ trạm tối thiểu tương ứng. Các bước để phân tích suy thoái mạng -Monte Carlo như sau:

Bước 1: Thiết lập mục tiêu giám sát và tiêu chí đánh giá:

Bước 2: Chọn mạng giám sát sẽ được đánh giá và các yếu tố được sử dụng trong phân tích.

Bước 3: Chuẩn hóa dữ liệu giám sát trong quá khứ cho các yếu tố đã chọn.

Bước 4: Đối với mỗi yếu tố quá trình lấy mẫu và phân tích Monte Carlo được thực hiện như sau:

Bước 4a: Lấy mẫu ngẫu nhiên, không có sự lặp lại từ mạng lưới trạm đầy đủ để chọn các trạm mong muốn cho mạng giảm cấp. Một trạm chỉ có thể được chọn một lần trong cùng một mẫu.

Bước $4 \mathrm{~b}$ Tính toán giá trị yếu tố theo thời gian của một mẫu mạng giảm cấp từ các giá trị yếu tố giám sát.

$$
\hat{T}_{1}=\frac{1}{N s} \sum_{j=1}^{N s} T_{j}
$$

Trong đó $\hat{T}_{1}$ là chuỗi số liệu tổ hợp được xác định từ Ns trạm được lựa chọn ngẫu nhiên và $T_{j}$ là chuỗi số liệu trạm thứ j $(1 \leq \mathrm{Ns} \leq \mathrm{N}-1)$

Bước $4 \mathrm{c}$ : Tính toán các xu hướng tuyến tính của chuỗi số liệu tổ hợp cho mỗi lần thực hiện Ns; Tính toán hệ số tương quan giữa chuỗi số liệu tổ hợp và chuỗi số liệu giám sát của mạng cơ sở.

Bước 4d: Lặp lại các bước 4a đến 4c 10.000 lần để tạo các kịch bản mạng giảm cấp và tính toán sai số tuyệt đối trung bình (MAE) cho các xu hướng:

$$
M A E=\frac{1}{10000} \sum_{k=1}^{10000}\left|\frac{\Delta \bar{T}}{\Delta t}-\frac{\Delta \hat{T}_{k}}{\Delta t}\right|
$$

Trong đó $\Delta \overline{\mathrm{T}} / \Delta t$ là xu thế của chuỗi yếu tố giám sát của mạng cơ sở; $\Delta \hat{\mathrm{T}}_{\mathrm{k}} / \Delta t$ là xu thế của chuỗi số liệu tổ hợp của lần lấy mẫu thứ $\mathrm{k}$ của mạng lưới trạm giảm cấp có kích thước Ns.

Bước $4 \mathrm{e}$ : Lặp lại các bước $4 \mathrm{a}$ đến $4 \mathrm{~d}$ cho tất cả các kịch bản kích thước mạng giảm cấp có thể có $(\mathrm{Ns}=1,2,3, \ldots \mathrm{N}-1)$.

Bước 4f: Xác định mối quan hệ giữa sai số tuyệt đối trung bình và kích thước mạng giảm cấp bằng phương trình hồi quy và đồ thị giá trị MAE so với số lượng trạm. Biểu đồ cho thấy số lượng trạm cần thay đổi như thế nào với các mức sai số được xác định trước.

Bước $4 \mathrm{~g}$ : Từ mối quan hệ của bước $4 \mathrm{f}$, xác định số lượng trạm cần thiết cho các giá trị MAE đã chọn cho yếu tố. Tiêu chí lựa chọn số lượng trạm là chênh lệch giữa các xu hướng yếu tố được tính toán từ các mạng giảm kích thước và mạng cơ sở không lớn hơn giới hạn sai số định trước.

Bước 5: Lựa chọn các trạm trong mạng lưới trạm tham chiếu: Từ kết quả xác định được số lượng trạm tối ưu trong mạng lưới trạm tham chiếu lựa chọn tổ hợp các trạm phù hợp thỏa mãn đồng thời các tiêu chí : (1) Sai số của giá trị trung bình yếu tố có giá trị nhỏ nhất có thể; (2) Xu hướng biến đổi của yếu tố đồng pha và có sai số nhỏ nhất có thể; (3) Hệ số tương quan giữa hai chuỗi yếu tố của hai mạng lưới trạm lớn nhất có thể.

Từ kết quả rà soát các tiêu chí của tất cả các 
tổ hợp xây dựng chỉ tiêu tổng hợp để lựa chọn được tổ hợp các trạm phù hợp nhất theo chiến lược hạ dần mức độ của các chỉ tiêu để lựa chọn được một vài tổ hợp tối ưu nhất. Phân tích, đánh giá các tổ hợp này có xem xét đến tính phù hợp và đại biểu về phân bố không gian của các trạm trong tổ hợp trên vùng khí hậu để lựa chọn tổ hợp trạm tối ưu nhất cho trong mạng lưới trạm trạm tham chiếu. tố.

Bước 6: Lặp lại các bước 4 và 5 cho từng yếu

Bước 7: Tổng hợp các kết quả lựa chọn mạng trạm tối ưu của tất cả các yếu tố thành mạng lưới trạm khí tượng tham chiếu phục vụ việc giám sát $\mathrm{BĐKH}$ và tác động $\mathrm{BĐKH}$ đến yếu tố cực trị và hiện tượng khí tượng nguy hiểm.

Bước 8: Đánh giá lại mạng tối ưu được chọn.

\section{Kết quả và phân tích}

Các nghiên cứu sâu về BĐKH và tác động BĐKH đến các yếu tố cực trị và hiện tượng khí tượng nguy hiểm thông qua các chỉ số cho thấy các yếu tố chính trực tiếp và gián liên quan đến đánh giá tác động $\mathrm{BĐKH} \mathrm{đến} \mathrm{các} \mathrm{yếu} \mathrm{tố} \mathrm{cực} \mathrm{trị}$ và hiện tượng khí tượng nguy hiểm là: tổng lượng mưa, nhiệt độ trung bình, cao nhất, thấp nhất năm. Mục tiêu của việc xây dựng mạng lưới trạm khí tượng tham chiếu là giám sát $\mathrm{BĐKH}$ và tác động của $\mathrm{BĐKH} \mathrm{đến} \mathrm{các} \mathrm{yếu} \mathrm{tố} \mathrm{cực} \mathrm{trị} \mathrm{và}$ hiện tượng khí tượng nguy hiểm tại khu vực Nam Bộ thông qua giám sát xu thế biến đổi của các yếu tố khí tượng là nhiệt độ trung bình năm, nhiệt độ cao nhất năm, nhiệt độ thấp nhất năm và tổng lượng mưa năm. Tiêu chí lựa chọn mạng trạm tham chiếu tối ưu là sai số của xu hướng biến đổi nhiệt độ trung bình, cao nhất, thấp nhất được tính toán từ mạng giảm cấp và từ mạng đầy đủ nhỏ hơn $0,05{ }^{\circ} \mathrm{C} /$ thập kỷ và sai số của $\mathrm{xu}$ hướng biến đổi lượng mưa hàng năm nhỏ hơn 1\%/thập kỷ.

Phân tích số liệu nhiệt độ trung bình, nhiệt độ cao nhất, nhiệt độ thấp nhất của các trạm cơ bản trên vùng khí hậu Nam Bộ (hình 2) cho thấy nhiệt độ trung bình tại các trạm trong khu vực đã tăng lên trong vòng 39 năm qua với tốc độ trung bình là $0,21^{\circ} \mathrm{C} /$ thập kỷ. Nhiệt độ cao nhất tăng với tốc độ trung bình là $0,12^{\circ} \mathrm{C} /$ thập kỷ. Nhiệt độ thấp nhất tăng với tốc độ trung bình là 0,16 ${ }^{\circ} \mathrm{C} /$ thập kỷ. Ngược lại, tổng lượng mưa năm giảm hầu hết ở các trạm trên khu vực với tốc độ trung bình toàn khu vực là $6,43 \% /$ thập kỷ. Các số liệu nhiệt độ trung bình năm, nhiệt độ ngày lớn nhất năm, nhiệt độ ngày nhỏ nhất năm, tổng lượng mưa được chuẩn hóa làm đầu vào để lựa chọn mạng trạm tối ưu.

Thực hiện lấy mẫu và phân tích Monte Carlo đối với mạng 16 trạm khí tượng trên khu vực. Đối với mỗi mật độ (kích thước) mạng trạm giảm cấp Ns (Ns biến đổi từ 1 đến 15$)$, các tập hợp trạm được chọn ngẫu nhiên từ toàn bộ mạng lưới trạm để tạo ra các kịch bản mạng trạm giảm cấp $[2,3]$. Số lần lựa chọn ngẫu nhiên là 10.000 lần nhằm đảm bảo tất cả tập hợp có thể có của các trạm đều được lựa chọn. Việc lấy mẫu được thực hiện không lặp lại, một trạm chỉ có thể được chọn một lần trong một mẫu. Đối với mỗi mẫu lựa chọn ngẫu nhiên, tính toán chuỗi yếu tố theo không gian theo công thức 1 và xác định xu thế biến đổi của yếu tố cho từng mẫu. Đối với mỗi kích thước mạng tính toán sai số tuyệt đối trung bình của xu thế biến đổi theo công thức (2). Từ các kết quả tính toán sai số trung bình của từng mạng trạm giảm cấp, xây dựng phương trình hồi quy giữa sai số tuyệt đối trung bình và mật độ mạng trạm giảm cấp cho các yếu tố. Phương trình hồi quy sử dụng đa thức bậc bốn cung cấp sự phù hợp tốt hơn các đa thức bậc thấp, đặc biệt là cho mật độ mạng trạm nhỏ. Kết quả xác định quan hệ giữa sai số tuyệt đối trung bình và mật độ mạng trạm giảm cấp cho các yếu tố được trình bày trong hình 3 . 


\section{BÀI BÁO KHOA HỌC}

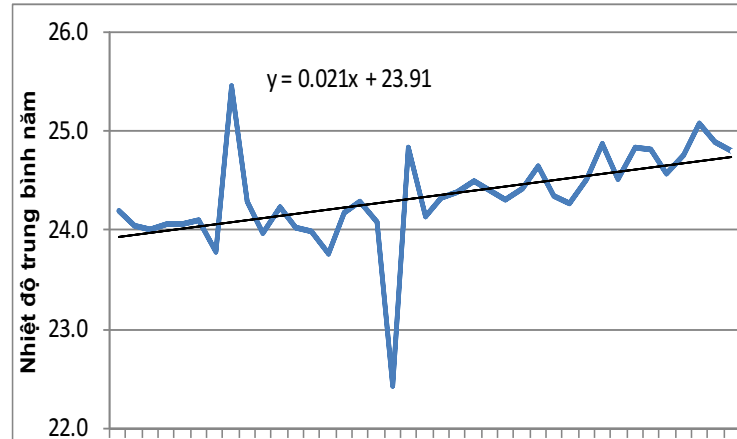

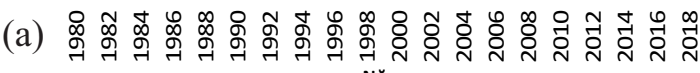
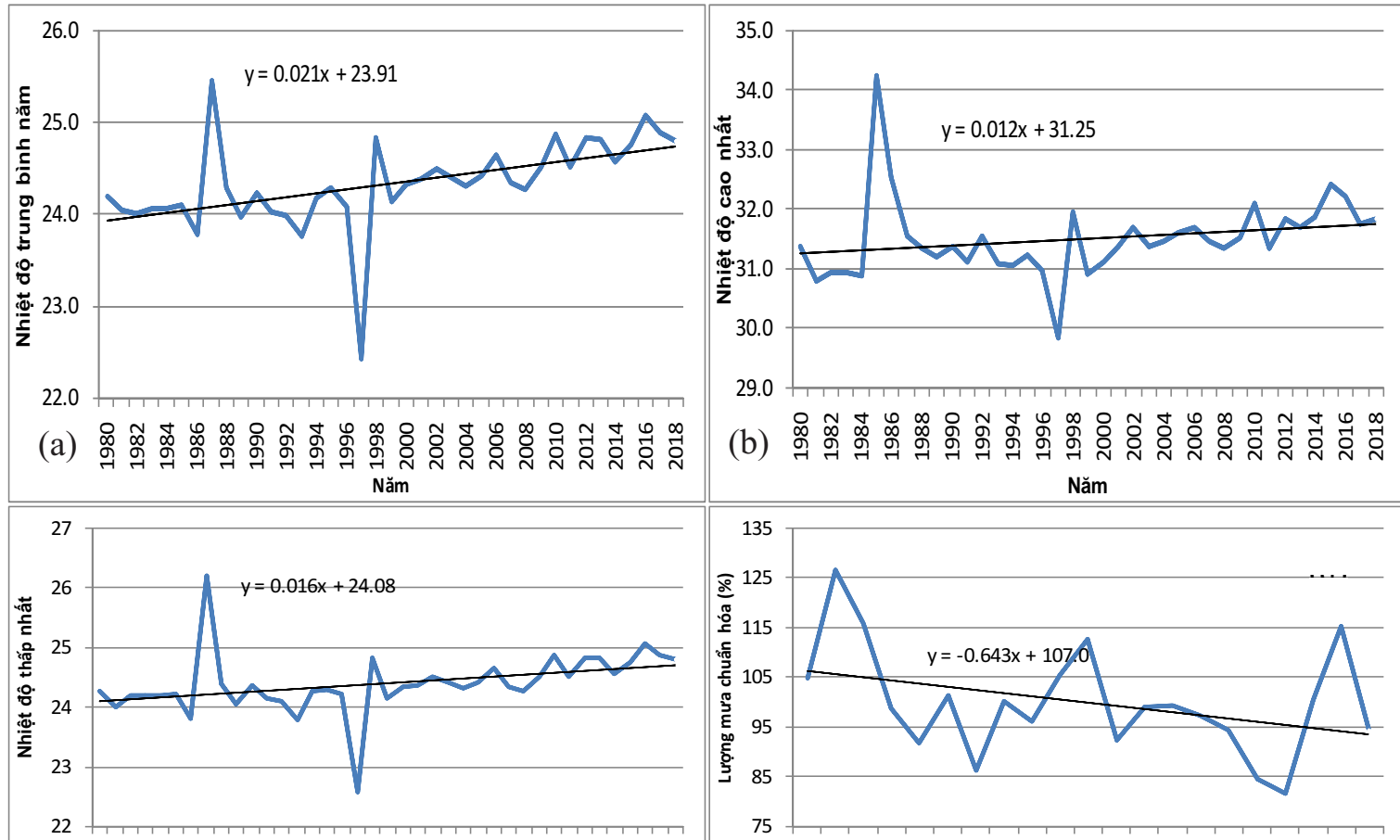

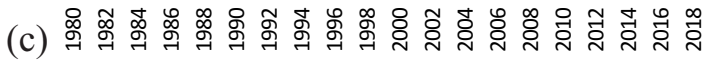
Năm

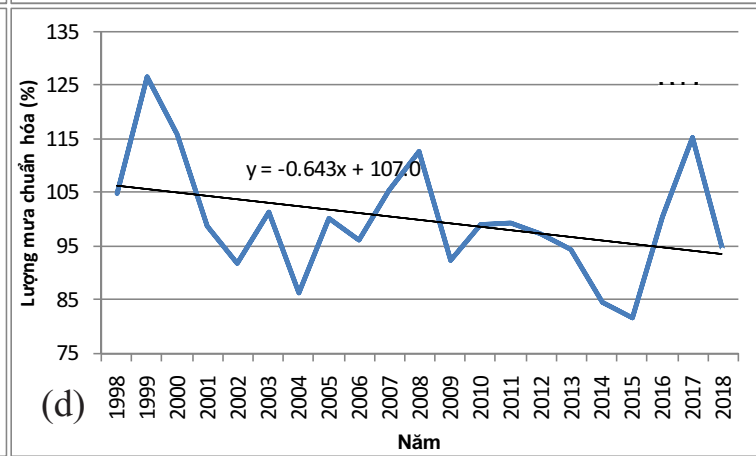

Hình 2. Xu thế biến đổi của các yếu tố trên vùng khí hậu Nam bộ trong giai đoạn tù 1980 - 2018:

(a) Nhiệt độ trung bình năm; (b) Nhiệt độ cao nhất năm; (c) Nhiệt độ thấp nhất năm;

(d) Tổng lượng mưa năm

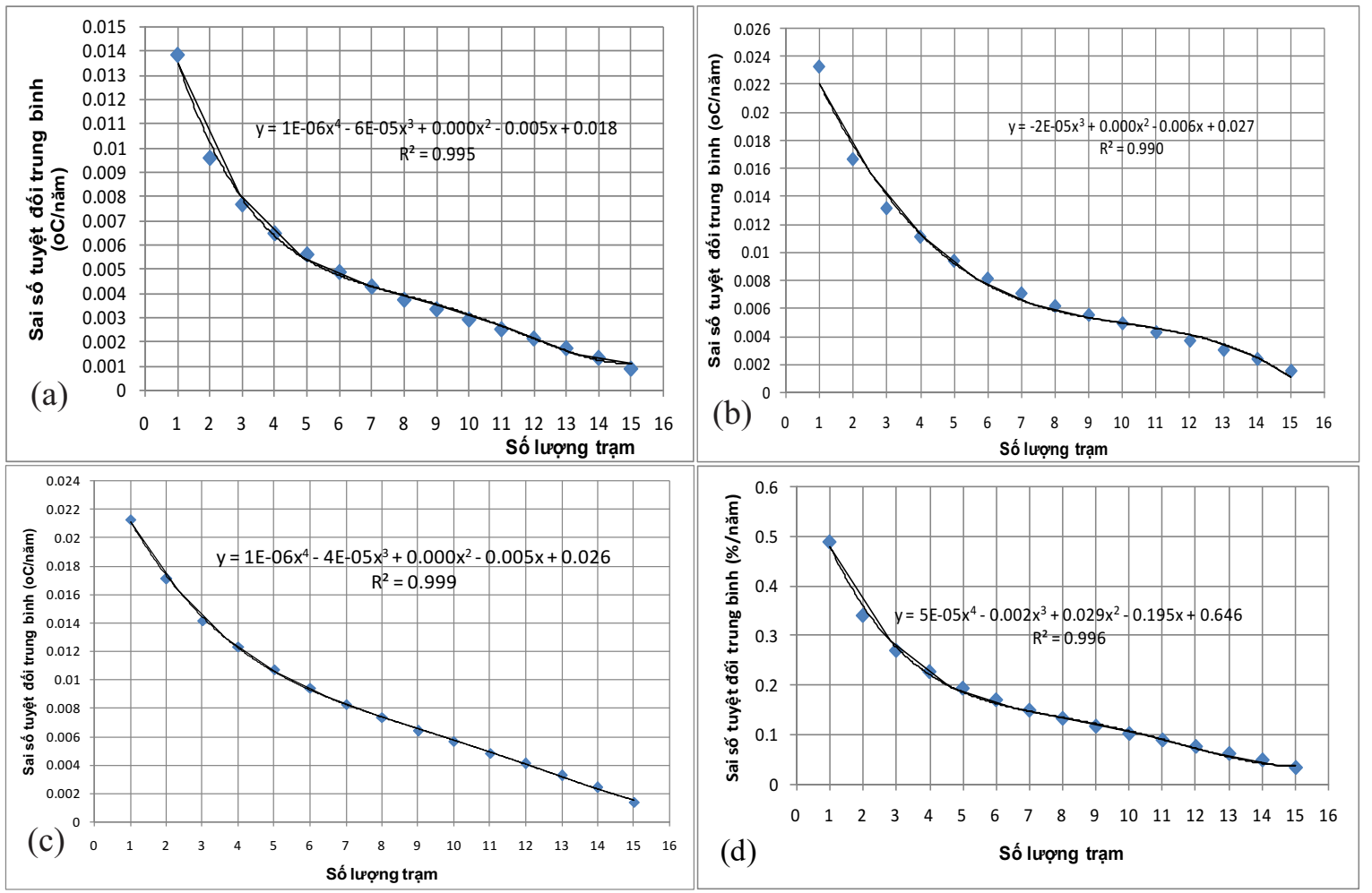

Hình 3. Quan hệ giữa sai số tuyệt đối trung bình và mật độ mạng trạm giảm cấp: (a) đối với nhiệt độ trung bình; (b) đối với nhiệt độ cao nhất; (c) đối với nhiệt độ thấp nhất; (d) đối với luợng mura 
Các kết quả tính toán cho thấy đối với tất cả các yếu tố, sai số tuyệt đối trung bình (MAE) giảm khi mật độ mạng trạm giảm cấp tiếp cận mật độ mạng cơ sở (Hình 3). MAE giảm nhanh khi Ns tăng trên một số lượng nhỏ các trạm và giảm chậm hơn khi Ns tiếp cận $\mathrm{N}$. Kết quả cho thấy có thể có những cải thiện lớn về hiệu suất mạng trong trường hợp tăng từ một đến ba trạm trên khu vực. Cần xem xét lợi ích tiềm năng này trong việc tối ưu hóa giữa các nguồn lực và mục tiêu khoa học. Các kết quả trên hình 3 cho thấy mật độ mạng tăng lên, kết quả của các mục tiêu giám sát chính xác hơn, đã làm giảm sự chênh lệch tuyệt đối giữa xu hướng của mạng giảm cấp và xu hướng của mạng cơ bản.

Phân tích sai số tuyệt đối trung bình tối thiểu, tối đa và độ lệch chuẩn của xu hướng yếu tố nhiệt độ trung bình được lấy từ 10.000 lần thực hiện Monte Carlo cho mỗi kích thước mạng (Hình 4) cho thấy nếu lựa chọn 6 trạm cho vùng nghiên cứu nhiệt độ trung bình có xu thế biến đồi trong phạm vi $0.034^{\circ} \mathrm{C} /$ thập kỷ đến $0,36^{\circ} \mathrm{C} /$ thập kỷ với độ lệch chuẩn là $0,059^{\circ} \mathrm{C} /$ thập kỷ trong khi lựa chọn mật độ 10 trạm cho thấy nhiệt độ trung bình có xu thế trong phạm vi $0,182^{\circ} \mathrm{C}$ với độ lệch chuẩn $0,0035^{\circ} \mathrm{C} /$ thập kỷ. Điều này cho thấy sai số xu thế ước tính của khu vực đã giảm và trở nên gần với xu thế quan sát của khu vực hơn khi số lượng trạm trong khu vực tăng lên. Độ lệch chuẩn và chênh lệch tối đa của ước tính xu thế cho thấy việc áp dụng các mục tiêu giám sát nghiêm ngặt hơn đã cải thiện hiệu suất mạng giảm cấp.
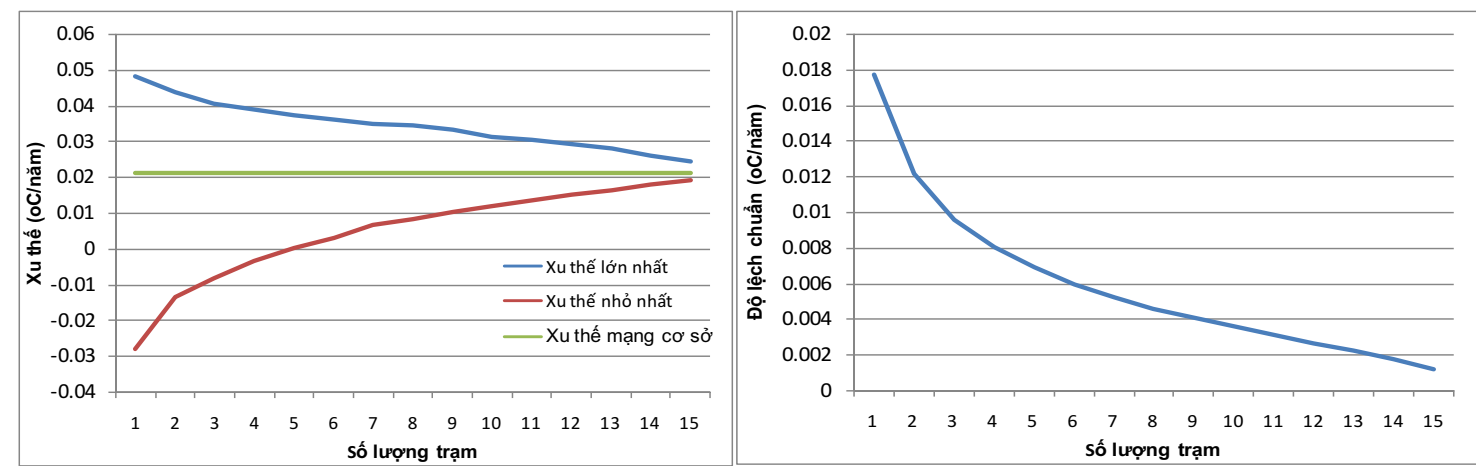

Hình 4. Sai số tuyệt đối trung bình tối thiểu, tối đa và độ lệch chuẩn của xu hướng yếu tố nhiệt độ trung bình.

Đặt mục tiêu giám sát sau đó giải phương trình đa thức để xác định mật độ trạm tối ưu trong khu vực. Để xác định tính nhạy cảm với cấu hình mạng và mật độ mạng, các mục tiêu giám sát xu hướng nhiệt độ và lượng mưa hàng

Bảng 1. Số lương trạm ưng với các mục tiêu giám sát xu hướng nhiệt độ và lương mura hàng năm.

\begin{tabular}{lcccc}
\hline Mục tiêu chọn & \multicolumn{4}{c}{ Số lượng trạm giám sát } \\
\cline { 2 - 5 } & $\begin{array}{c}\text { Nhiệt độ } \\
\text { trung bình }\end{array}$ & $\begin{array}{c}\text { Nhiệt độ́ } \\
\text { cao nhất }\end{array}$ & $\begin{array}{c}\text { Nhiệt độ́ } \\
\text { thấp nhất }\end{array}$ & $\begin{array}{c}\text { Tổng lượng } \\
\text { mưa }\end{array}$ \\
\hline $\begin{array}{l}0,05^{\circ} \mathrm{C} / \text { thập kỷ } \\
1 \% / \text { thập kỷ }\end{array}$ & 5 & 10 & 11 & 10 \\
$\begin{array}{l}0,1^{\circ} \mathrm{C} / \text { thập kỷ } \\
2 \% / \text { thập kỷ }\end{array}$ & 3 & 5 & 6 & 5 \\
\hline
\end{tabular}


Các mạng lưới trạm khí tượng đáp ứng mục tiêu $0,05^{\circ} \mathrm{C} /$ thập kỷ bao gồm 6 trạm giám sát nhiệt độ trung bình, 10 trạm giám sát nhiệt độ cao nhất và 11 trạm giám sát nhiệt độ thấp nhất. Mạng lưới trạm khí tượng tham chiếu đáp ứng mục tiêu 1\%/thập kỷ bao gồm 10 trạm giám sát lượng mưa.

Lựa chọn tổ hợp các trạm phù hợp trong vùng khí hậu phụ thuộc vào kiến thức về $\mathrm{BĐKH}$ và tác động khí hậu và sự thay đổi khí hậu theo không gian trong vùng. Xác định được số lượng trạm tối ưu đối với các yếu tố nhiệt độ trung bình, cao nhất, thấp nhất và lượng mưa sẽ xác định được số tổ hợp của các trạm có thể có của mạng trạm tối ưu đối với từng yếu tố. Cụ thể sẽ có 3003 tổ hợp đối với nhiệt độ trung bình, nhiệt độ cao nhất và lượng mưa; 1365 tổ hợp đối với nhiệt độ thấp nhất. Đối với mỗi yếu tố, tính toán các tiêu chí lựa chọn gồm mức độ chênh lệch của giá trị trung bình trong 39 năm, mức độ sai số của xu thế so với mạng cơ bản và hệ số tương quan với chuỗi số liệu của mạng trạm cơ bản cho từng tổ hợp.

Lựa chọn các tổ hợp trạm thỏa mãn đồng thời các tiêu chí chặt chẽ nhất gồm sai số của giá trị trung bình yếu tố từ kết quả tính toán giữa mạng tham chiếu và mạng cơ sở có giá trị nhỏ nhất có thể; Xu hướng biến đổi của yếu tố giữa hai mạng lưới trạm đồng pha và có sai số nhỏ nhất có thể và Hệ số tương quan giữa hai chuỗi yếu tố của hai mạng lưới trạm lớn nhất có thể. Có thể thấy rằng đối với cả 4 yếu tố, không có tổ hợp nào có thể đồng thời đạt cả 3 tiêu chí là sai số giá trị trung bình giữa kết quả tính toán của mạng tham chiếu và mạng cơ sở là nhỏ nhất, xu hướng biến đổi của yếu tố đồng pha và có sai số nhỏ nhất và hệ số tương quan của mạng tham chiếu và mạng cơ sở là lớn nhất. Từ kết quả rà soát các tiêu chí của tất cả các tổ hợp xây dựng được tiêu chí tổng hợp tiệm cận với tiêu chí tối ưu nhất theo chiến lược hạ dần mức độ của các tiêu chí. Các tiêu chí tổng hợp này được sửa dụng để lựa chọn được tổ hợp các trạm tối ưu trong mạng lưới trạm trạm tham chiếu. Kết quả đã lựa chọn được từ 1 đến 3 tổ hợp tối ưu và có các điều kiện chặt chẽ nhất cho các yếu tố. Qua phân tích, đánh giá chỉ tiêu tổng hợp được chọn là $\{\Delta \mathrm{TB}<0,003 ; \Delta \mathrm{XT}<$ $0,001 ; \mathrm{r} 2>0,92\}$ tương ứng lựa chọn được tổ hợp trạm tối ưu gồm 5 trạm là Cà Mau, Châu Đốc, Cần Thơ, Mộc Hóa, Sóc Trăng, Rạch Giá với giá trị các chỉ số là $\{\Delta \mathrm{TB}=0,0016 ; \Delta \mathrm{XT}$ $=0,000666 ; \mathrm{r} 2=0,921\}$. Phân tích trên bản đồ thấy rằng tổ hợp trạm tối ưu được chọn để giám sát yếu tố nhiệt độ trung bình có phân bố tương đối đồng đều theo không gian, đáp ứng được các yêu cầu về tính đại biểu cho các tiêu vùng khí hậu (hình 5). Tương tự, phân tích và lựa chọn được tổ hợp mạng trạm tối ưu cho các yếu tố khác như trong bảng 2 .

Bảng 2. Kết quả lựa chọn tổ hợp trạm tối ưu cho các yếu tố

\begin{tabular}{|c|c|c|c|}
\hline Yếu tố & Tiêu chí chọn & \multicolumn{2}{|c|}{ Tổ hợp trạm thỏa mãn điều kiện } \\
\hline & & Danh sách trạm trạm & Thông số \\
\hline $\begin{array}{l}\text { Nhiệt độ trung } \\
\text { bình }\end{array}$ & $\begin{array}{l}\Delta_{\mathrm{TB}}<0,003 \\
\Delta_{\mathrm{XT}}<0,001 \\
\mathrm{r}^{2}>0,92\end{array}$ & $\begin{array}{l}\text { Châu Đốc, Cà Mau, Mộc Hóa, Vũng Tàu, } \\
\text { Tây Ninh, Cần Thơ }\end{array}$ & $\begin{aligned} \Delta \mathrm{TB} & =0,0016 \\
\Delta \mathrm{XT} & =0,000666 \\
\mathrm{r}^{2} & =0,921\end{aligned}$ \\
\hline $\begin{array}{l}\text { Nhiệt độ cao } \\
\text { nhất }\end{array}$ & $\begin{array}{l}\Delta_{\mathrm{TB}}<0,001 \\
\Delta \Delta_{\mathrm{XT}}<0,0002 \\
\mathrm{r}^{2}>0,99\end{array}$ & $\begin{array}{l}\text { Càng Long,Sóc Trăng, Tây Ninh, Vũng } \\
\text { Tàu,Côn Đảo, Mộc Hóa,Cà Mau, Cần } \\
\text { Tho, Mỹ Tho,Phú Quốc }\end{array}$ & $\begin{array}{c}\Delta_{\mathrm{TB}}=0,000577 \\
\Delta_{\mathrm{XT}}=0,000175 \\
\mathrm{r}^{2}=0,990951\end{array}$ \\
\hline $\begin{array}{l}\text { Nhiệt độ thấp } \\
\text { nhất }\end{array}$ & $\begin{array}{l}\Delta_{\mathrm{TB}}<0,002 \\
\Delta_{\mathrm{XT}}<0,0001 \\
\mathrm{r}^{2}>0,98\end{array}$ & $\begin{array}{l}\text { Bạc Liêu,Cà Mau, Châu Đốc, Côn Đảo, } \\
\text { Mộc Hóa, Mỹ Tho, Phú Quốc, Phước } \\
\text { Long, Vũng Tàu, Tây Ninh, Sóc Trăng }\end{array}$ & $\begin{aligned} \Delta_{\mathrm{TB}} & =0,001836 \\
\Delta_{\mathrm{XT}} & =0,0000745 \\
\mathrm{r}^{2} & =0,9882\end{aligned}$ \\
\hline $\begin{array}{l}\text { Tổng lượng } \\
\text { mưa }\end{array}$ & $\begin{array}{l}\Delta_{\mathrm{TB}}<0,0001 \\
\Delta \mathrm{XT}<0,0001 \\
\mathrm{r}^{2}>0,95\end{array}$ & $\begin{array}{l}\text { Phước Long, Vũng Tàu, Côn Đảo, Mộc } \\
\text { Hóa, Càng Long,Châu Đốc, Sóc Trăng, } \\
\text { Cần Tho, Rạch Giá, Bạc Liêu }\end{array}$ & $\begin{aligned} \Delta_{\mathrm{TB}} & =0,0000119 \\
\Delta_{\mathrm{XT}} & =0,0000719 \\
\mathrm{r}^{2} & =0,9667\end{aligned}$ \\
\hline
\end{tabular}




\section{BÀI BÁO KHOA HỌC}

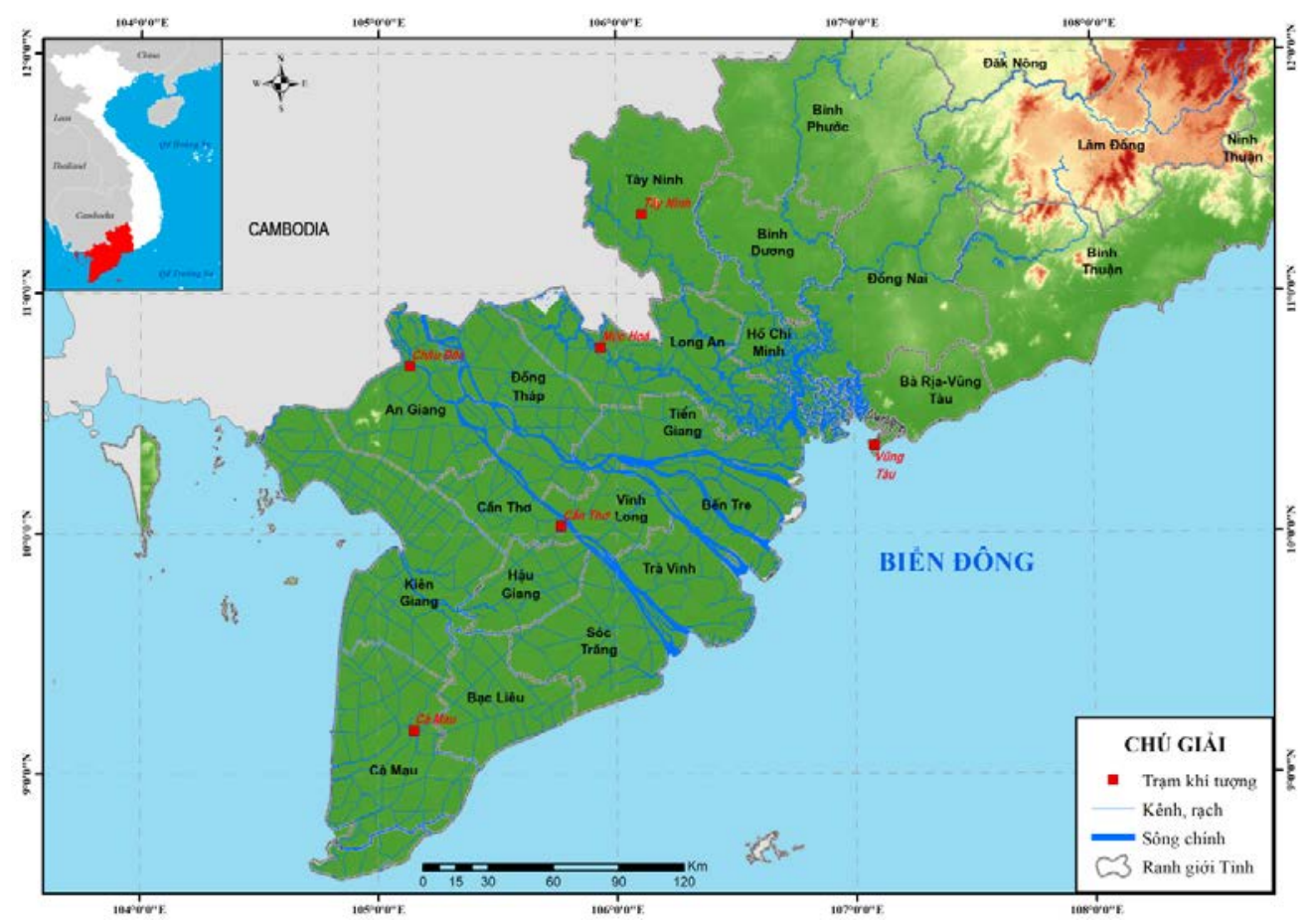

Hình 5. Vị trí tổ hợp trạm tối ưu cho nhiệt độ trung bình

Từ các kết quả lựa lựa chọn mạng trạm tối ưu chọn được mạng trạm khí tượng tham chiếu như giám sát đối với từng yếu tố lượng mưa và nhiệt bảng 3 và hình 6 .

độ trong các bảng 2 , tổng hợp và phân tích lựa

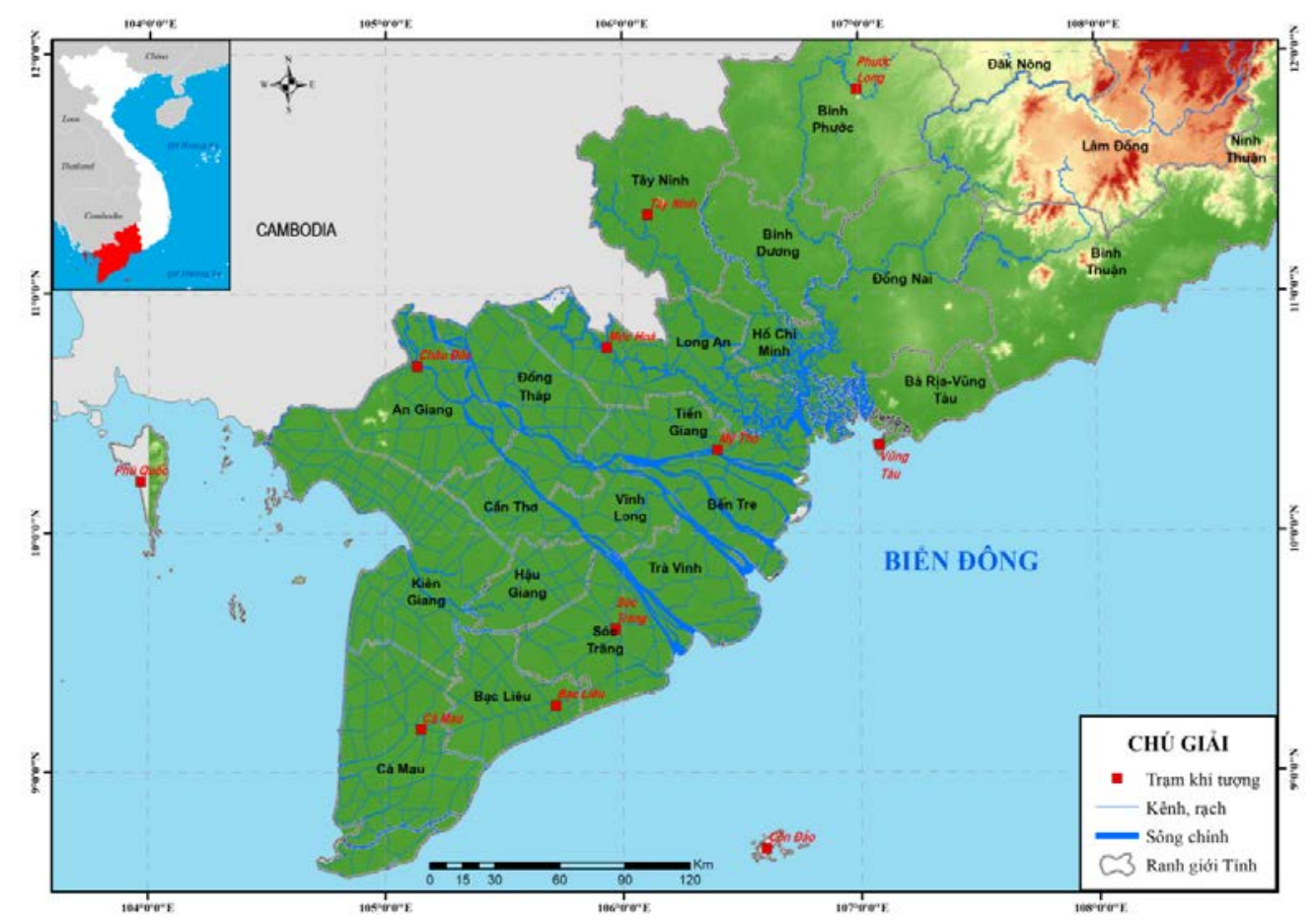

Hình 6. Vị trí các trạm khí tương trong mạng trạm khí hậu tham chiếu 
BÀI BÁO KHOA HỌC

Bảng 3. Vị trí trạm khi tuợng thuộc vùng khí hậu Nam bộ trong mạng trạm khi tuợng tham chiếu

\begin{tabular}{|c|c|c|c|c|c|c|c|c|c|}
\hline TT & Tên trạm & Tỉnh & Kinh độ & Vĩ độ & TT & Tên trạm & Tỉnh & Kinh độ & Vĩ độ \\
\hline 1 & Phước Long & Bình Phước & $106^{\circ} 59^{\prime}$ & $11^{\circ} 50^{\prime}$ & 6 & Mỹ Tho & $\begin{array}{c}\text { Tiền } \\
\text { Giang }\end{array}$ & $106^{\circ} 24^{\prime}$ & $10^{\circ} 21^{\prime}$ \\
\hline 2 & Tây Ninh & Tây Ninh & $106^{\circ} 07^{\prime}$ & $11^{\circ} 20^{\prime}$ & 7 & Châu Đốc & An Giang & $105^{\circ} 08^{\prime}$ & $10^{\circ} 42^{\prime}$ \\
\hline 3 & Vũng Tàu & $\begin{array}{l}\text { Bà Rịa- } \\
\text { Vũng tàu }\end{array}$ & $107^{\circ} 05^{\prime}$ & $10^{\circ} 22^{\prime}$ & 8 & Sóc Trăng & Sóc Trăng & $105^{\circ} 58^{\prime}$ & $9^{\circ} 36^{\prime}$ \\
\hline 4 & Côn Đảo & $\begin{array}{l}\text { Bà Rịa- } \\
\text { Vũng tàu }\end{array}$ & $106^{\circ} 36^{\prime}$ & $8^{\circ} 41^{\prime}$ & 9 & Phú Quốc & $\begin{array}{l}\text { Kiên } \\
\text { Giang }\end{array}$ & $103^{\circ} 58^{\prime}$ & $10^{\circ} 13^{\prime}$ \\
\hline \multirow[t]{2}{*}{5} & Mộc Hóa & Long An & $105^{\circ} 56^{\prime}$ & $10^{\circ} 47^{\prime}$ & 10 & Bạc Liêu & Bạc Liêu & $105^{\circ} 43^{\prime}$ & $9^{\circ} 17^{\prime}$ \\
\hline & & & & & 11 & Cà Mau & Cà Mau & $105^{\circ} 09^{\prime}$ & $9^{\circ} 11^{\prime}$ \\
\hline
\end{tabular}

Mục tiêu chính của mạng tham chiếu cho vùng khí hậu Nam Bộ là giám sát sự thay đổi khí hậu trong tương lai. Các chỉ tiêu thống kê được sử dụng để mô tả khả năng tái mô phỏng các yếu tố của mạng tham chiếu so với mạng cơ bản gồm hệ số tương quan $\left(\mathrm{r}^{2}\right)$, sự sai khác của xu thế và chênh lệch giá trị trung bình. Kết quả tính toán các chỉ tiêu cho 4 yếu tố này được thể hiện ở bảng 4. Kết quả phân tích này chỉ ra rằng mạng trạm tham chiếu được lựa chọn có thể mô phỏng tốt xu thế biến đổi khí hậu như mạng cơ bản với độ trung thực cao. Hệ số tương quan được tạo bởi mạng tham chiếu cao trên 97,4\% đối với nhiệt độ và đạt $98,5 \%$ đối với lượng mưa, chênh lệch giá trị trung bình của yếu tố nhiệt độ của mạng trạm tham chiếu nhỏ hơn $0,071^{\circ} \mathrm{C}$ đối với nhiệt độ và $0,043 \%$ đối với lượng mưa. Mạng tham chiếu cũng có hiệu quả trong việc định lượng sự thay đổi khí hậu. Xu hướng của nhiệt độ trung bình, cao nhất, thấp nhất chênh lệch từ 0,00075 đến $0,05^{\circ} \mathrm{C} /$ thập kỷ so với mạng cơ bản. $\mathrm{Xu}$ hướng lượng mưa chênh lệch trong vòng 0,0042\%/thập kỷ so với mạng cơ bản (Bảng 4).

Bảng 4. Kết quả đánh giá mạng khỉ hậu tham chiếu cho vùng khí hậu Nam Bộ

\begin{tabular}{|c|c|c|c|c|c|c|c|c|}
\hline \multirow{2}{*}{ Chỉ số } & \multicolumn{2}{|c|}{ Nhiệt độ cao nhất } & \multicolumn{2}{|c|}{ Nhiệt độ thấp nhất } & \multicolumn{2}{|c|}{$\begin{array}{l}\text { Nhiệt độ trung } \\
\text { bình }\end{array}$} & \multicolumn{2}{|c|}{ Tổng lượng mưa } \\
\hline & $\mathrm{T}_{\max }$ & sai số & $\mathrm{T}_{\min }$ & sai số & $\mathrm{T}_{\mathrm{tb}}$ & sai số & $\mathrm{X}$ & sai số \\
\hline Trung bình & 31,58 & 0,0709 & 24,4 & 0,00184 & 27,24 & 0,0337 & 1976 & 0,043 \\
\hline Hệ số góc & 0,00735 & 0,00541 & 0,0159 & 0,0000745 & 0,0216 & 0,00353 & $-12,39$ & 0,000415 \\
\hline Hệ số tương quan & \multicolumn{2}{|c|}{0.974} & \multicolumn{2}{|c|}{0,988} & \multicolumn{2}{|c|}{0,976} & \multicolumn{2}{|c|}{0,985} \\
\hline
\end{tabular}

\section{Kết luận}

Phân tích suy thoái mạng Monte Carlo là một phương pháp được sử dụng tương đối rộng rãi để xác định mạng lưới trạm khí tượng tham chiếu phục vụ giám sát BĐKH. Sự giảm cấp của mật độ mạng có thể được sử dụng để xác định mối quan hệ giữa mật độ trạm và hiệu suất mạng. Phương pháp sử dụng dữ liệu mạng cơ bản trong quá khứ để có thể tính toán sự khác biệt thống kê của các mạng giảm cấp. Biểu đồ ước tính sai số tuyệt đối trung bình cho các kịch bản mạng giảm cấp khác nhau được xây dựng. Trên cơ sở đó số lượng trạm và tổ hợp các trạm tối ưu được xác định thông qua phân tích các tiêu chí giám sát.
Phương pháp suy thoái mạng Monte Carlo và quy trình xác định mạng trạm tối ưu được ứng dụng để xác định mạng trạm khí tượng tham chiếu phục vụ giám sát BĐKH cho vùng khí hậu Nam bộ. Kết quả cho thấy mạng tham chiếu bao gồm 11 trạm như trong hình 6 cho phép giám sát được các xu thế biến đổi của các yếu tố nhiệt độ cực trị và lượng mưa với giới hạn sai số cho phép là $0,05^{\circ} \mathrm{C} /$ thập kỷ đối với các yếu tố nhiệt độ và 1\%/thập kỷ đối với lượng mưa trung bình năm. Hiệu suất của các mạng giảm cấp được đánh giá và đảm bảo đáp ứng yêu cầu giám sát biến đổi khí hậu và tác động $\mathrm{BĐKH}$ cần thiết đối với vùng khí hậu Nam bộ. 
Lời cảm ơn: Bài báo được hoàn thành nhờ sụ hỗ trọ của đề tài BĐKH.24/16-20 trong việc nghiên cứu và công bố nhũng kết quả này.

\title{
Tài liệu tham khảo
}

1. Kunkel, K.E., Karl, T.R., Easterling, D.R. (2007), A Monte Carlo assessment of uncertainties in heavy precipitation frequency variations. Journal of Hydrometeorology 8, 1152-11601.

2.Vose, R.S., Menne, M.J. (2004), A method to determine station density requirements for climate observing networks. J. Climate, 17, 2961-2971.

3. Willmott, C.J., Robeson, S.M., Janis,M.J. (1996), Comparison of approaches for estimating time-averaged precipitation using data from the USA. Int. J. Climatol., 16, 1103-1115.

4. Robeson, S.M., Janis, M.J. (1998), Comparison of temporal and unresolved spatial variability in multiyear time-averages of air temperature. Climate Res., 10, 15-26.

5. Janis, M.J., Hubbard, K.G., Redmond, K.T. (2002), Determining the Optimal Number of Stations for the United States Climate Reference Network Final Report to NOAA/NCDC,2002.

6. Nguyễn Đức Ngữ, Nguyễn Trọng Hiệu (2004), Khí hậu và tài nguyên khi hậu Việt Nam. NXB Nông nghiệp, Hà Nội.

7. Janis, M.J., Hubbard, K.G., Redmond, K.T. (2004), Station density strategy for monitoring long-term climatic change in the contiguous United States. J. Climate, 17, 151-162

\section{SELECTION A REFERENCE CLIMATE NETWORK FOR MONITORING IMPACTS OF CLIMATE CHANGE IN NAM BO CLIMATE REGION}

\section{Dang Thanh Mai ${ }^{1}$}

${ }^{1}$ Viet Nam Meteorological and Hydrological Administration

\begin{abstract}
Climate Reference Network which includes meteorological stations is established to monitoring climatic change and impacts of climate change. Goal of this network is to provide homogeneous observations of temperature and precipitation from benchmark stations that can be coupled with historical observations for detection and attribution of climatic change. This study proposes a method and procedure to sellect the number and distribution of observing sites for the Climate Reference Network in Nam Bo climate region. The research was conducted by forming hypothetical networks from existing higher-density baseline network. Monte Carlo resampling techniques were applied to stations in the region to successively lower the resolution compared to that in the baseline network. The appropriate number of reference stations is defined as the number of stations needed to recreate, within the predetermined error limits, annual temperature and rainfall trends in the region. The selection of a set of stations is based on the analysis and evaluation of the criteria on average value error, trend error, correlation coefficient computed from reducedsize networks and the full-size networks and space distribution of stations. The optimal set of stations is determined separately for monitoring annual average temperature, highest temperature, lowest temperature and total rainfall. The reference climate network for the Southern region consists of 11 selected meteorological stations that meet the target of temperature change trend of $0,05^{\circ} \mathrm{C} /$ decade and the target of changing trend of total rainfall is 1,0\%/decade.
\end{abstract}

Keywords: Climate reference network, climate change monitoring, Southern climate region. 